\title{
Implementation of a Novel Educational Modeling Approach for Cloud Computing
}

\author{
http://dx.doi.org/10.3991/ijet.v9i6.4153 \\ Sara Ouahabi, Ahmed Eddaoui, El Houssine Labriji, Elhabib Benlahmar, Kamal El Guemmat \\ University of Hassan II - Mohammedia - Casablanca, Morocco
}

\begin{abstract}
The Cloud model is cost-effective because customers pay for their actual usage without upfront costs, and scalable because it can be used more or less depending on the customers' needs. Due to its advantages, Cloud has been increasingly adopted in many areas, such as banking, ecommerce, retail industry, and academy. For education, cloud is used to manage the large volume of educational resources produced across many universities in the cloud. Keep interoperability between content in an inter-university Cloud is not always easy. Diffusion of pedagogical contents on the Cloud by different E-Learning institutions leads to heterogeneous content which influence the quality of teaching offered by university to teachers and learners. From this reason, comes the idea of using IMS-LD coupled with metadata in the cloud. This paper presents the implementation of our previous educational modeling by combining an application in J2EE with Reload editor that consists of modeling heterogeneous content in the cloud. The new approach that we followed focuses on keeping interoperability between Educational Cloud content for teachers and learners and facilitates the task of identification, reuse, sharing, adapting teaching and learning resources in the Cloud.
\end{abstract}

Index Terms-Cloud, Education, Interoperability, ELearning, IMS-LD, Metadata.

\section{INTRODUCTION}

Cloud computing is an emerging new computing paradigm for delivering computing services. This computing approach relies on a number of existing technologies, the internet, virtualization, grid computing, web services, etc.

The use of Cloud for E-Learning offers several advantages to overcome the constraints of E-Learning systems especially at the technical level [1].

Create a learning experience to the student and to the tutor, based on the configuration of a set of elements in a specific period is not always easy. Thus, if we add the aspect of cloud computing in universities, diffusion of training modules on the cloud by various institutions causes heterogeneous systems which affect the educational quality offered by university to teachers and learners.

In this paper we present a new model of IMS-LD to adopt the heterogeneous content of E-learning in the cloud, the model keep the interoperability, facilitate the task of identifying, reusing, sharing and adaptation of learning and teaching resources in the cloud.

From our analysis, we found that the benefit of universities is limited in economic and technical advantages of cloud forgetting educational level.

We thought to provide a model, to manage a new pedagogical service, which will be useful for education.
We aim to implement a prototype of our model that combine E-learning with cloud computing by using IMSLD language as support, and at the same time teachers can work together to improve the quality of the training provided to learners; thus there are benefits for teachers and learners.

We benefit of metadata techniques to extract the supports courses.

This paper is organized as follows. Section II describes issues of using cloud computing in education. The section III describes IMS-LD specification and its benefits for Cloud. Section IV focuses on the implementation of interoperability model with IMS-LD in cloud. Section V ends this paper with Conclusion and Perspective.

\section{USING CLOUd COMPUTING FOR E-LEARNING}

One of the most interesting applications of cloud computing is educational cloud $[2,3,4,5]$.

Educational cloud computing providers are offering higher education the opportunity to substitute a presence in "the cloud" for universities' existing data centers, servers, and applications, replacing these machines' traditional "physical" presence on campus [6].

Educational cloud computing services represent a growing variety of useful services available on the internet and the most innovative and rapidly developing portion of the technology and education. It also promises to provide a variety of services that will be very useful to faculty, staff and students [7].

A large university might become a provider of cloud services. More often, individual campuses will obtain services from the cloud. The trend toward greater use of mobile devices also supports cloud computing because it provides access to applications, storage, and other resources to users from nearly any device [8].

There are three categories of services that may be offered in cloud computing:

- IaaS (infrastructure as a service): This is the lowest level service. It is to provide access to a virtualized IT infrastructure.

- PaaS (platform as a service): In this type of service, located just above the previous, the operating system and infrastructure tools are the responsibility of the supplier. The consumer control application and can add their own tools.

- SaaS (software as a service): In this type of service, applications are made available to consumers.

Concerning cloud models, we can distinguish four different types: 
a) Private Cloud: The Cloud infrastructure is provisioned for a single organization. It can be managed by the organization itself (internal Private Cloud) or mutualized; in this case a trusted provider supports some outsourced services (external Private Cloud).

b) Public Cloud: This type of infrastructure is accessible to a wide public and belongs to a provider of "cloud services". These services are free or offered on a pay-per-use model, the level of service being defined by the provider and it the same for all users.

c) Community Cloud: The infrastructure is shared by several organizations with common concerns (security, compliance, jurisdiction, etc.), it can be managed internally or by a third-party and hosted internally or externally...

d) Hybrid Cloud: Hybrid cloud is a composition of two or more clouds (private, community or public) that remain unique entities but are bound together, offering the benefits of multiple deployment models.

The architectural pattern of using Cloud Computing in universities may be described starting from the development and supply of Cloud Computing services and the resources offered to the university cf.Figure 1 [9].

We have several models to manage this architecture, In [6] offer Massive Centralized Cloud Computing (MCCC) scenario for educational institutions and our previous Educational cloud model [1], that combines the different tasks of the actors in the institutions and within the cloud computing.

\section{EdUCATIONAL Modeling}

\section{A. IMS-Learning Design}

The development of E-learning solutions includes steps to design of two types throughout the instructional design process [10] didactic method that focuses on the knowledge and Instructional Systems Design that focuses on the implementation of strategies around situations learning. Modeling of learning environments is to use the paradigm of learning objects and rely on a script with the notions of unit learning, resources and learning activities.

IMS-LD was published in 2003 by the IMS / GLC. (Instructional Management Systems Global Learning Consortium: Consortium for global learning with systems management training, the original name, when IMS started in 1997 was Instructional Management Systems project).

This specification allows representing and encoding learning structures for learners both alone and in groups, collected by roles, such as "learners" and "Team" [11]. We can model a lesson plan in IMS -LD, defining roles, learning activities, services and several other components.

This static model of learning design focuses on three entities cf.Figure2 [12]: roles, activities and environment. At the base:

- Roles: As a learner and facilitator (teacher, tutor, and facilitator) are played by people described by their properties.

- Activities : Performed by roles, they are part of a tree structure called method, decomposed into alternative pathways themselves broken down into sequential acts, each act is composed of partitions each defined by a role and activity. All partitions form the scenario of the Act which is usually composed of a structure of activities, which contains other structures activities to the learning activities or terminal supporting activities.

Environments: Includes all types of Learning Objects (LO) or services used by the roles in the activities and the results produced by the roles in the activities.
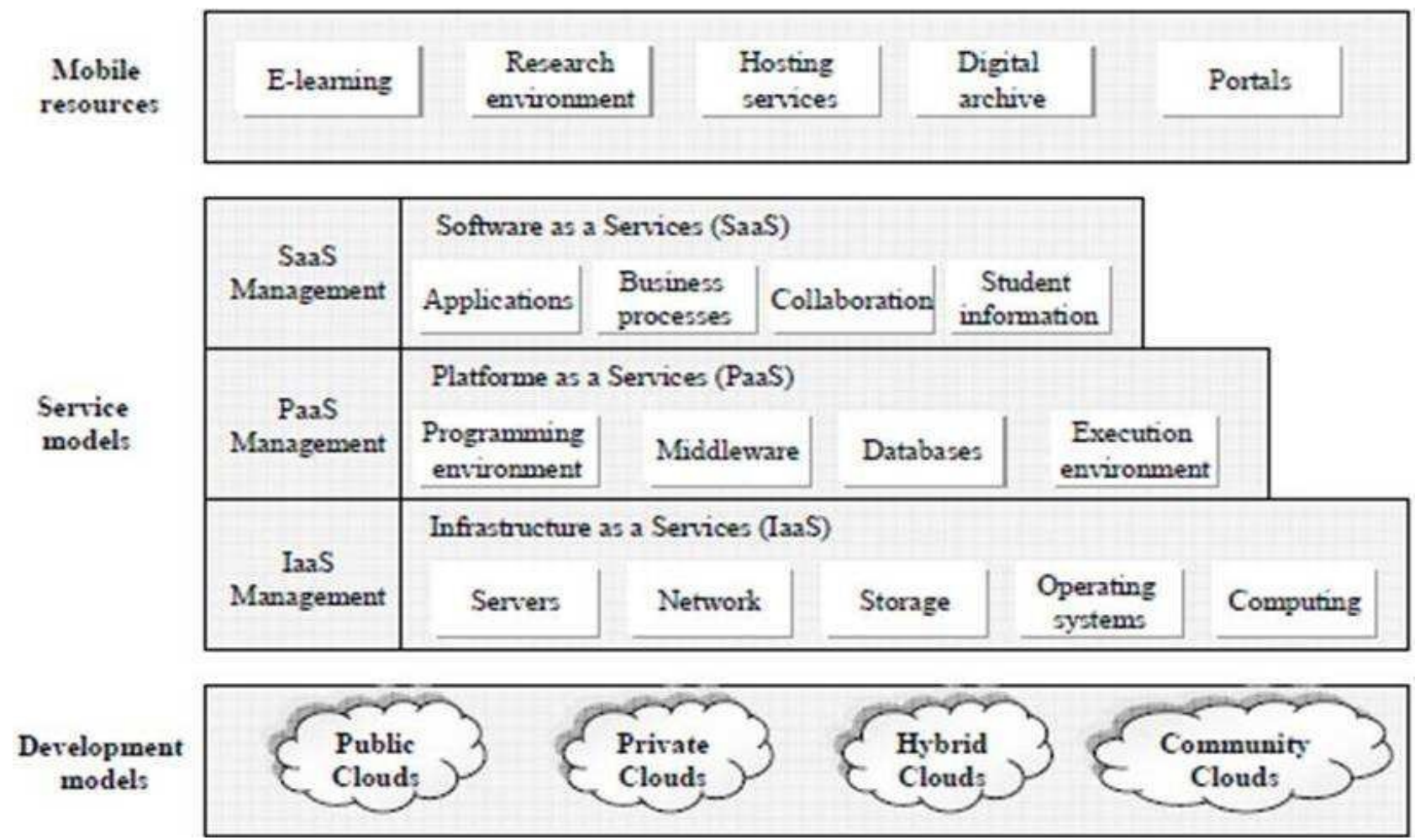

Figure 1. Cloud Architecture for University 


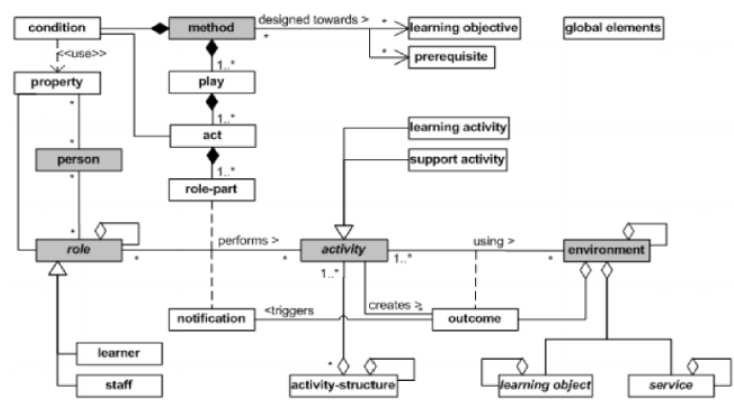

Figure 2. The conceptual model of IMS LD

\section{B. Standard of Educational modeling}

Three approaches focus on the concept of learning object defined as any entity, digital or non-digital, which can be used, re-used or referenced during technology supported learning [13].

LOM is an indexing language for data, its purpose is to make production profitable and develop reuse (economic perspective). SCORM allows exploiting the resource in a computer system and monitoring its use (technical perspective) and finally the educational modeling languages, among the most powerful languages of modeling we found IMS-LD, it refers to the quality by integrating learning objects in the design of learning situations (pedagogical perspective).

\section{IMPLEMENTATION OF INTEROPERABILITY MODEL IN THE CLOUD}

\section{A. Description of our Approach of educational modeling in the Cloud}

We found several studies concerned using Subject Teaching (online courses, course materials, etc...) In distributed architectures whose warehouse distributed based on the description of Learning Objects (LOs) by metadata LOM [14] which aims to make the LO easily accessible, usable and reusable.

Another work that speaks of modeling large warehouses LOs through DBpedia categories to automate the classification of LOs [15], the aim is to link the text fields based on the IEEE LOM that describe subjects of the LO, which are contained in the Universia [16] digital library with a set of semantic categories described in DBpedia.

However, the implementation of systems in the cloud didn't cover modeling of education by IMS-LD. Our study is focused in this area to analyze the contribution of modeling in Cloud computing which is rich in terms of teaching and learning resources architecture [17].

Suppose a Cloud cf. Figure 3 [18] contains several universities, our question is how we can benefit from these resources and maintain interoperability, to facilitate the identification task, reuse, sharing and adaptation of teaching and learning resources in the cloud.

Each student follows a course with the possibility to have similar proposals of support courses from different universities to complete and enrich their knowledge.

Teachers can also collaborate with other teachers and use their courses from cloud.

The new approach proposed of Educational Modeling cf. Figure 4 consists to describe the learning scenar-

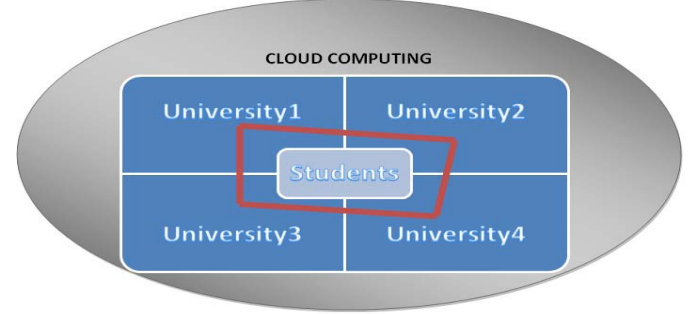

Figure 3. Cloud and educational modeling

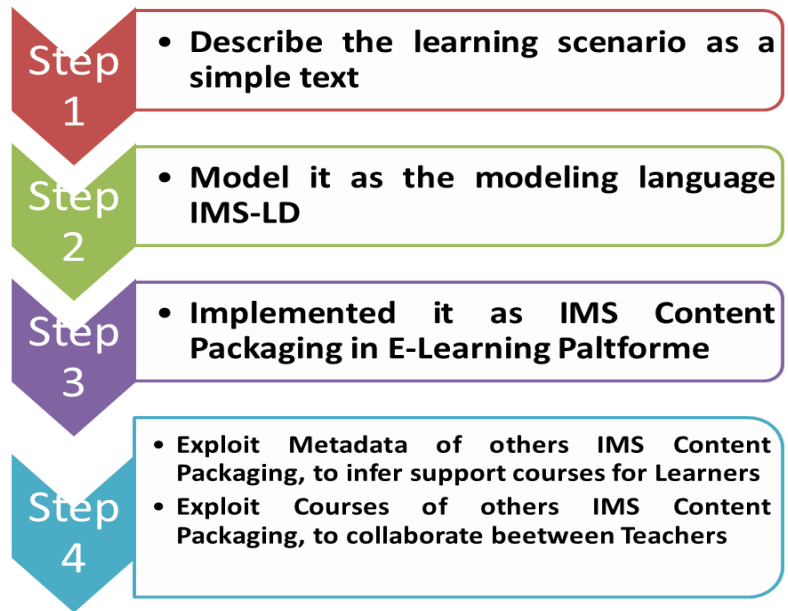

Figure 4. Approach of educational modeling in the Cloud

io as a simple text, model it using the IMS-LD already explained in the section III and implement it as IMS Content Packaging to ensure adaptation and interoperability, after exploit metadata of others Act, to infer support courses for learners, and exploit courses of others IMS Content Packaging to collaborate between teachers.

\section{B. Example of a Learning scenario in the Cloud (Case of support)}

To validate our model we give in the following an example of modeling a Learning scenario 'LS' in the cloud according to IMS-LD [19].

\section{1) Text of the Example}

- The learners will read the course in an Educational Cloud with the assistance of their tutors.

- At the same time, they can view available courses in other universities for support and for reinforce their acquired.

- $\quad$ Then, they must pass an online control while answering a series of questions.

2) Text transformation in a standard IMS-LD

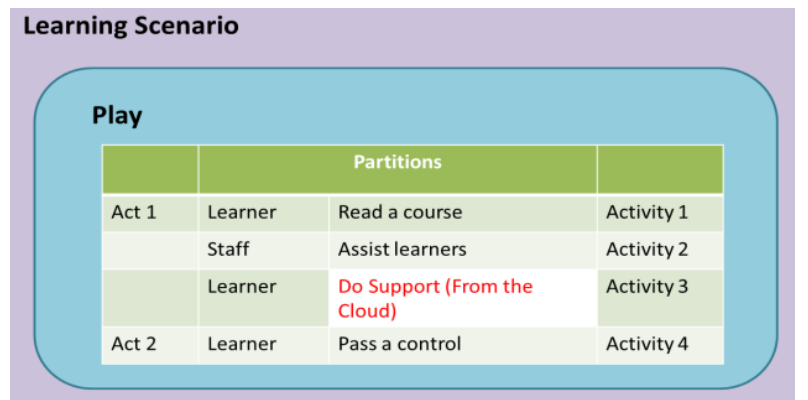

Figure 5. Example of Learning Scenario 
3) Activity diagram of the Learning Scenario

Act 1

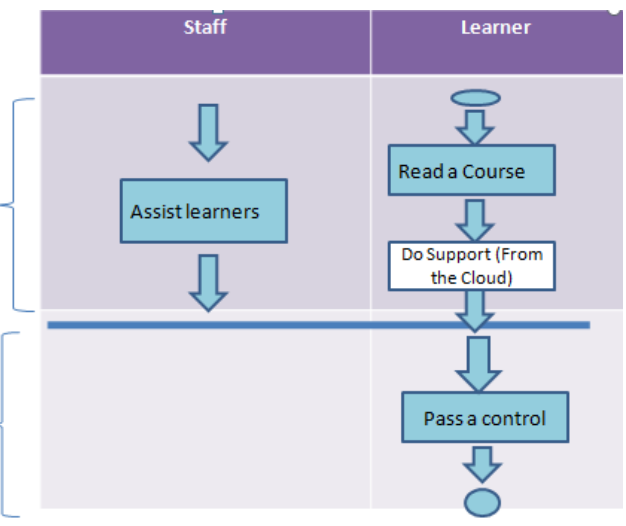

Figure 6. Activity diagram of the LS

What is interesting in the figures 5 and 6 is the white part, provides support for learner in the Cloud, to complete and enrich their knowledge.

4) Schema of the Act 1 generated by the MOTPLUS software

MOTPLUS used to model a learning activity level A.

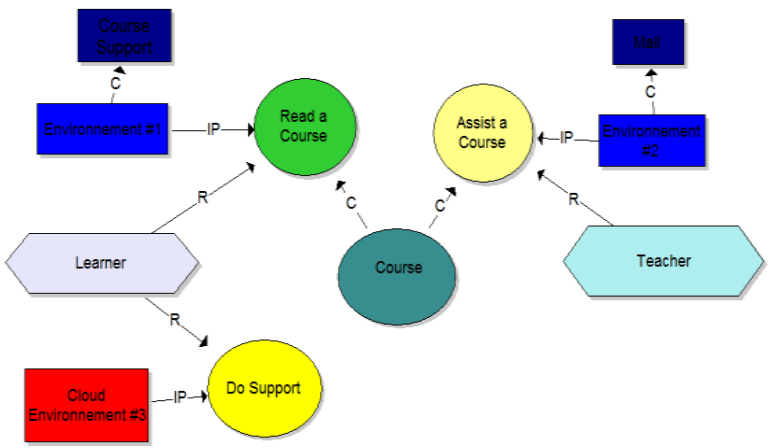

Figure 7. Schema of the Act 1 by MOT+

\section{Implementation of solution}

For the implementation part is to encapsulate the Learning Scenario as IMS Content Packaging by reload editor, exploit it by the student and infer support courses from various universities of cloud cf. Figure 8.

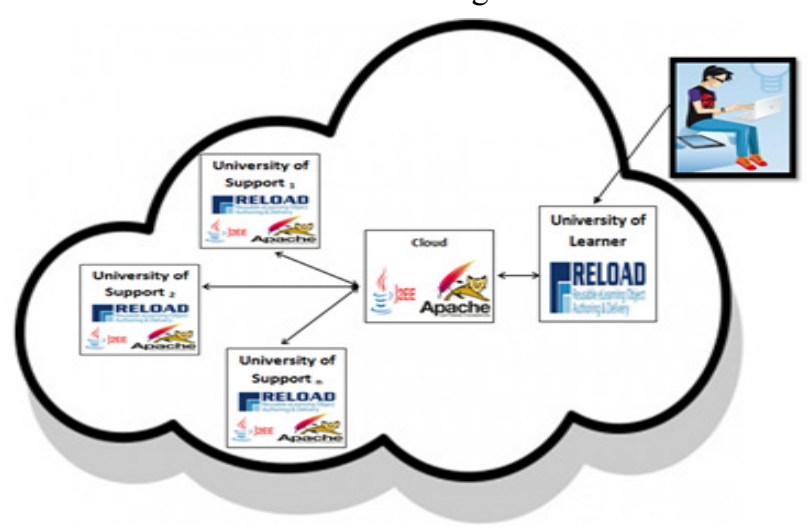

Figure 8. Schema of our implementation

The responsible for the service in the learner's university, has created IMS Content Packaging (under the name, imsetudiant) in the reload editor cf. Figure 9, i.e. he created act 1 and 2 already explained.

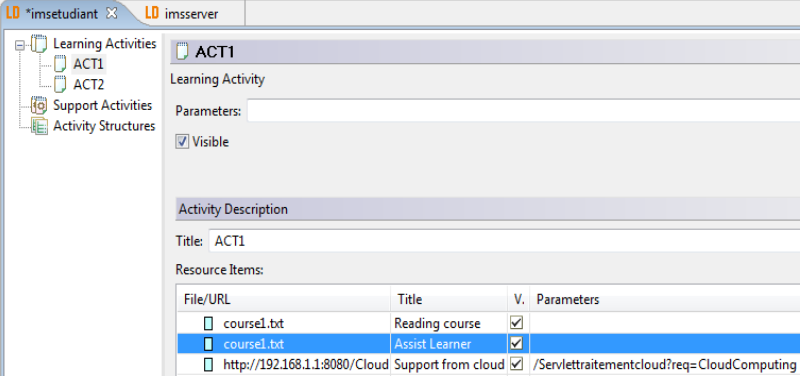

Figure 9. Create IMS Content Packaging in Reload Editor

In act1, we indicated the local link of courses for activities 1 and 2, for Activity 3 of support, we indicated URL to a central servlet named 'Servlet traitement cloud' (http://192.168.1.1:8080/Cloud/Servlettraitement cloud?req=CloudComputing) that is executed in a Cloud, and developed in J2EE cf.Figure10 with a web server Tomcat. This servlet shares control with other servlets running in universities of support to find the additional course.

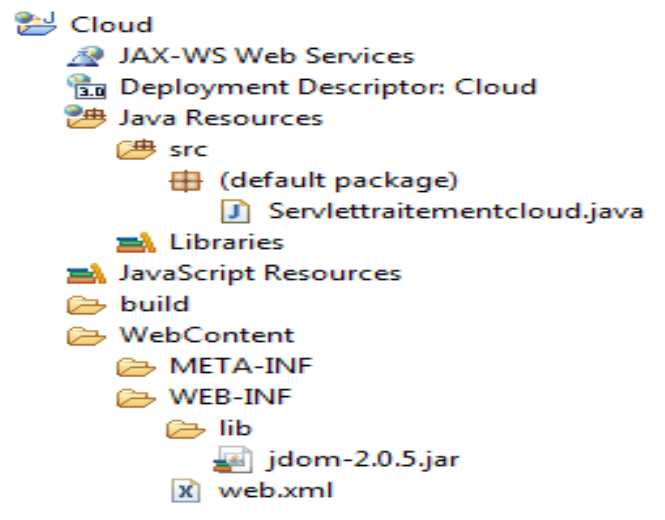

Figure 10. Web application (Cloud)developed in J2EE

In the servlet, there is the parameter(req = Cloud Computing) to look for similar courses which talks about Cloud Computing, but to find the course in question, we must define the metadata in each act of the cloud cf.Figure11.

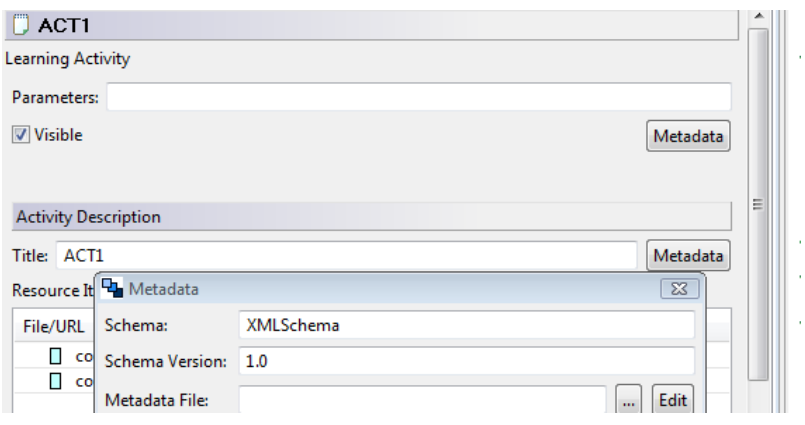

Figure 11. Act metadata

I.e. the servlet search in all universities of cloud the manifest.xml file (each manifest.xml contains the information of an IMS Content Packaging called imsserver and which included metadata of acts cf.Figure12).

For each university of support the servlet search in the file manifest.xml of each imsserver (there may be several packages in the same university) the tag imsld: word act (there may be several acts in the same package) by the org.dom2 API, if the servlet detects that one act can serve 
the learner, it appears the URL of the support courses, else if the servlet cannot find anything it displays "we find nothing".

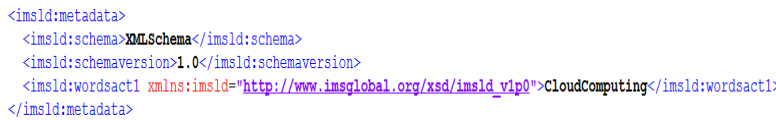

Figure 12. Act metadata in manifest.xml

Figure below shows the imsetudiant executed by reload player simulating E-learning system, which requires the student in act 3 to check course in universityl of support.

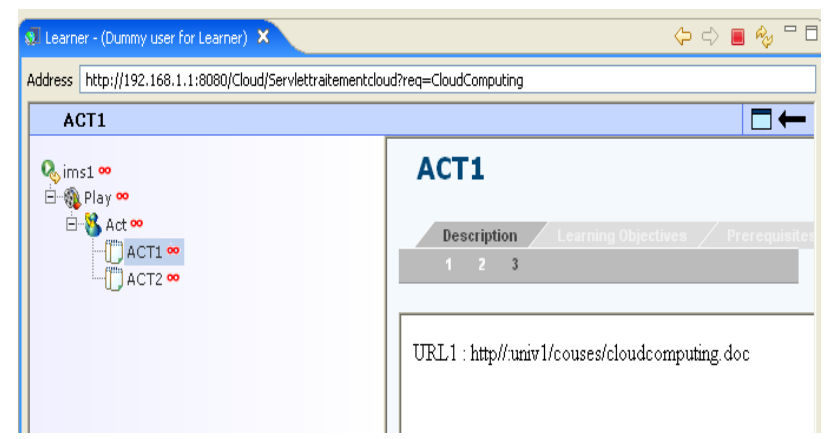

Figure 13. Imsetudiant executed by reload player

We showed an example of support, for the scenario of collaboration between teachers, task is simpler, as the teacher detects an important course in another university, and they should contact the owner of the course, after he includes it in its IMS Content Packaging by indicating its URL.

\section{Conclusion And Perspective}

Cloud computing is a new emerging technology that is expected to significantly change the field of IT.

In this article, we define the advantages and the general context of using E-learning in the cloud according to IMSLD specification.

To manage the courses in Cloud Computing, we have proposed a new model which brings many benefits to the pedagogical level such as collaboration between teachers and learners.

We have implemented our model in an educational cloud that will be used for any categories and different types of educational cloud especially PaaS and Community Cloud. We have to do a student's and teacher's surveys to make the advantages that can give our model for them.

It remains to find the ideal solution to adapt IMS-LD in Cloud Computing, automating the work of actors and manage interoperability, for that we think to use for next step indexing techniques.

\section{REFERENCES}

[1] Sara OUAHABI, Ahmed EDDAOUI, Hassan LABRIJI, 'CLOUD COMPUTING FOR IMPROVING E-LEARNING', International Journal of Science and Advanced Technology, 2013

[2] "How can cloud computing help in education", http://www.cloudtweaks.com/2011/02/how-cancloud- computinghelp-in-education/, 2001

[3] Dan Morill, "Cloud Computing in Education", http://www.cloudave.com/14857/cloud-computingin- education/, 2011.
[4] Marinela M. and Anca A. "Using Cloud Computing in Higher Education: A Strategy to Improve Agility in the Current Financial Crisis", 2011 http://www.ibimapublishing.com/journals/CIBIMA/2011/875547/ 875547.pdf

[5] John P. "Cloud computing - what is it and what does it mean for education?"http://erevolution.jiscinvolve.org/wp/files/2009/07/cloudsjohnpowell.pdf

[6] Sasikala, S., Prema, S., 2010. Massive Centralized Cloud Computing (Mccc) Exploration in Higher Education, In:Advances in Computational Sciences \& Technology, 3 (2): 111-118.

[7] Cloud Computing Services: Appropriate use of online software tools such as Google Apps, Gmail, and Microsoft Live Office by the Michigan State University Community,http://lct.msu.edu/documents/CloudComputingatMSU,guidance document,6Sep2011.pdf

[8] Praveena, K., Betsy, T., 2009. Application Of Cloud Computing in Academia, In: Iup Journal Of Systems Management, 7 (3): 50-54.

[9] Marinela Mircea, Anca Ioana Andreescu."Using Cloud Computing in Higher Education: A Strategy to Improve Agility in the Current Financial Crisis",Volume 2011 (2011), Article ID 875547, Communications of the IBIMA, 15 pages

[10] Paquette G. (2002) L'ingénierie du télé-apprentissage, pour construire l'apprentissage en réseaux, Presses de l'Université du Québec, mai 2002, 490 pages

[11] Daniel Burgos, Michel Arnaud, Patrick Neuhauser et Rob Koper, "IMS Learning Design : la flexibilité pédagogique au service des besoins de la e-formation"

[12] Lim Kin Chew, IMS Learning Design and eLearning, Proceedings of the Second International Conference on eLearning for Knowledge-Based Society, August 4-7, 2005, Bangkok, Thailand

[13] IEEE: Institute of Electrical and Electronics Engineers ,http://www.ieee.org/portal/site ,2001

[14] Nawel Iles, Azzeddine Chikh, Sidi Mohammed Chouiti, Construction d'un entrepôt de métadonnées - LOM Application: Elearning,

[15] Manuel Lama, Juan C. Vidal, Estefanía Otero-García, Alberto Bugarín and Senén Barro Semantic Linking of Learning Object repositories to DBpedia Educational Technology \& Society, 15 (4), 47-61.

[16] Universia (2012a). Biblioteca Universia Recursos Aprendizaje. Retrieved March 20, 2012, from http://biblioteca.universia.net

[17] OUAHABI, S. EDDAOUI, A. LABRIJI, H. BENLAHMAR, E and El Guemmat, K."Using IMS LD Specification for e-Learning in the Cloud Computing," International Journal of Information and Education Technology vol. 5, no. 11, pp. 860-864, 2015. http://dx.doi.org/10.7763/IJIET.2015.V5.627

[18] Sara OUAHABI, Ahmed EDDAOUI, El Houssine LABRIJI, Elhabib BENLAHMAR, Youssef FAHIM ; Adaptation of Distance Learning in the Cloud According to IMS LD Specification; International Conference on Multimedia Computing and Systems ; 2014.

[19] OUAHABI, S. EDDAOUI, A. LABRIJI, H. BENLAHMAR, E and El Guemmat, K. "EDUCATIONAL MODELLING IN CLOUD COMPUTING USING IMS LEARNING DESIGN", Journal of Theoretical and Applied Information Technology 31st August 2014 -- Vol. 66. No. 3 - 2014.

\section{AUTHORS}

Sara Ouahabi, Ahmed Eddaoui, El Houssine Labriji, Elhabib Benlahmar, and Kamal El Guemmat are with University of Hassan II - Mohammedia - Casablanca, Morocco.

Submitted 04 September 2014. Published as resubmitted by the authors 08 December 2014. 